\title{
Numerical Simulation Research on Distribution Characteristics of Overlying Rock Stress Field in Floor Roadway
}

\author{
ZHonghua Wang ${ }^{1,2, *}$ \\ ${ }^{1}$ National Key Laboratory of Gas Disaster Detecting, Preventing and Emergency Controlling, Chongqing 400037 \\ ${ }^{2}$ China Coal Technology Engineering Group Chongqing Research Institute, Chongqing 400037
}

\begin{abstract}
In order to explore the distribution characteristics of the overlying rock stress field in the floor roadway at different locations, FLAC3D software was used to simulate and analyze the surrounding rock directly above the floor roadway and the surrounding rock within $15 \mathrm{~m}$ on both sides of the floor roadway when the distance between the floor roadway and the coal roadway and the horizontal distance were changed. The stress field distribution characteristics are obtained, and the stress field distribution characteristics of different areas directly above and on both sides of the floor roadway are obtained, which provides a theoretical basis for the location selection and support of the floor roadway.
\end{abstract}

\section{Overview of the test area}

The floor lane of 213 along the channel is located at the level of $-850 \mathrm{~m}$, which belongs to the mining area of Xixiashan, and is not less than $8 \mathrm{~m}$ below the 213 channel. To the east is the west downhill, the 215 bottom tunnel and the west return wind down the hill, the west is the BF4 fault, the west second downhill unmined area, the south is the west downhill unmined area, and the north is the 211 working face mined out area. The purpose of roadway excavation: to drain 213 along the channel to ensure that the gas does not exceed the limit when 213 is tunneled along. The design length is $458 \mathrm{~m}$, and the service life is about 7 months. The underground elevation of the tunnel is $-968.449 \sim-999.447 \mathrm{~m}$, and the ground elevation is $+37 \mathrm{~m}$. The roadway opens to the west under the first return wind from the west, with a net cross-section of $3.8 \times 2.8 \mathrm{~m}$. The supporting forms are anchors, nets, beams, and anchor cables. The excavation is a whole rock, the lithology is mainly fine sandstone, gray-white, thin-medium-thick layered, calcareous argillaceous cement sandwiched thin layered mudstone, the rock is relatively broken, the rock strata strike $40-60^{\circ}$, incline SE, dip angle $12^{\circ}$. The mining area is B4 coal seam with a coal thickness of $2.6 \sim 3.0 \mathrm{~m}$. The coal seam in this mining area is generally monoclinic. The coal seam strikes $40-60^{\circ}$, inclines SW, and dips 10 $13^{\circ}$. The geological structure of this roadway is relatively complicated, and 7 faults are exposed during the driving process, with a drop of more than $2 \mathrm{~m}, 1$; and a drop of $0.3 \sim 1.3 \mathrm{~m}$, with 6 faults.

\section{Simulation scheme and parameter determination}

The simulation test adopts FLAC3D software, and the constitutive relationship of surrounding rock adopts Mohr-Coulomb criterion. The relevant parameters of the model are the actual parameters of the mining area. The simulation scheme is to change the vertical and horizontal distance between the floor roadway and the coal roadway respectively, extract the vertical stress cloud diagrams of the coal roadway roof and floor after the floor roadway and coal roadway are excavated, and calculate the vertical stress reduction curve. With reference to the existing research results at home and abroad ${ }^{1 \sim 5}$, it obtained the distribution characteristics of the overlying rock in the floor roadway. The vertical distance between the floor roadway and the coal roadway is $8 \mathrm{~m}, 10 \mathrm{~m}, 15 \mathrm{~m}, 25 \mathrm{~m}$; the horizontal distance between the two is $-10 \mathrm{~m}, 0 \mathrm{~m}, 10 \mathrm{~m}$, $20 \mathrm{~m}$, and -10 means that the floor roadway is $10 \mathrm{~m}$ outside the coal roadway in the horizontal direction., $0 \mathrm{~m}$ represents the floor roadway is directly below the coal roadway, $10 \mathrm{~m}$ represents that the floor roadway is staggered by $10 \mathrm{~m}$ in the horizontal direction, and $20 \mathrm{~m}$ represents the floor roadway is staggered by $20 \mathrm{~m}$ in the horizontal direction.

\footnotetext{
*Corresponding author’s e-mail: boaidajia2007@126.com
} 


\section{Stress distribution characteristics in the vertical direction}

\subsection{Vertical stress cloud diagram of surrounding rock of roadway}

When the method distances between floor roadway and coal roadway are $8 \mathrm{~m}, 10 \mathrm{~m}, 15 \mathrm{~m}$, and $25 \mathrm{~m}$ respectively, after the floor roadway and coal roadway are all excavated, the vertical stress cloud diagram of the roof and floor of the coal roadway is shown in Figure 1.

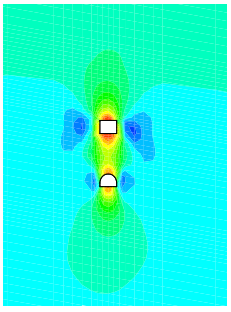

(a) $8 \mathrm{~m}$

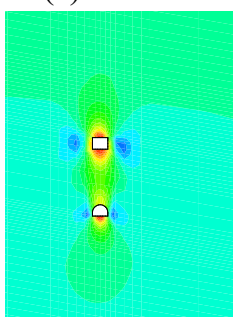

(c) $15 \mathrm{~m}$

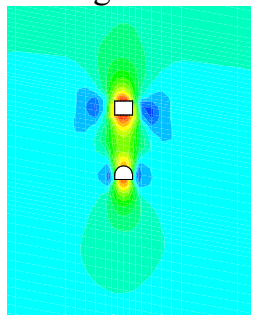

(b) $10 \mathrm{~m}$

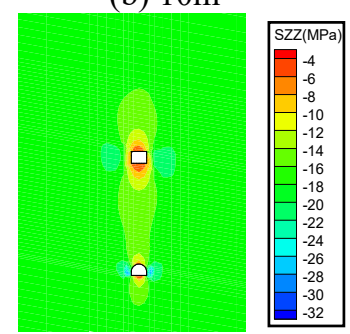

(d) $25 \mathrm{~m}$

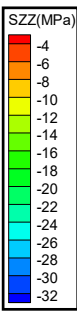

Figure 1. Vertical stress cloud diagram when the coal roadway and floor roadway are at different distances

\subsection{Analysis of stress field distribution characteristics}

When the method distance between floor roadway and coal roadway is $8 \mathrm{~m}, 10 \mathrm{~m}, 15 \mathrm{~m}, 25 \mathrm{~m}$, respectively, by extracting stress cloud map data, draw the vertical stress reduction curve of coal roadway roof after coal roadway excavation when different distances between coal roadway and floor roadway are drawn, as shown in Figure 2. Shown.

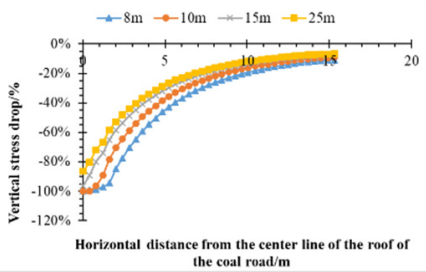

(a) Surrounding rock directly above

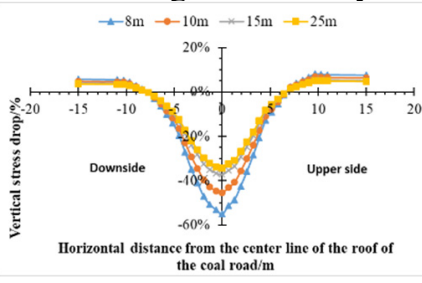

(b) Surrounding rock on both sides above

Figure 2. When the coal roadway and the floor roadway are at different distances from each other, the vertical stress reduction curve of the coal roadway roof after the coal roadway is driven
It can be seen from Figure 2(a) that after the coal roadway is excavated, when the distance between the floor roadway and the coal roadway is $8 \mathrm{~m}, 10 \mathrm{~m}, 15 \mathrm{~m}$, and $25 \mathrm{~m}$, respectively, within $15 \mathrm{~m}$ directly above the center line of the coal roadway roof, as the floor roadway is away from the coal roadway With the increase of the normal distance, the vertical stress drop gradually decreases. The vertical stress drop difference between the two normal distances of $8 \mathrm{~m}$ and $10 \mathrm{~m}, 10 \mathrm{~m}$ and $15 \mathrm{~m}, 15 \mathrm{~m}$ and $25 \mathrm{~m}$ gradually decreases, that is, the normal distance is $8 \mathrm{~m}$ and $10 \mathrm{~m}$. The vertical stress reduction curves at $15 \mathrm{~m}$ and $25 \mathrm{~m}$ gradually become dense, indicating that with the increase of the distance between the floor roadway and the coal roadway, the pressure relief effect of the surrounding rock directly above the floor roadway gradually weakens and the pressure relief speed gradually slows down.

It can be seen from Figure 2 (b) that when the distance between the floor roadway and the coal roadway is $8 \mathrm{~m}$, $10 \mathrm{~m}, 15 \mathrm{~m}$, and $25 \mathrm{~m}$ respectively, the vertical stresses of the surrounding rocks on both sides of the top of the coal roadway roof centerline are reduced by $55 \%, 45 \%$, and 37 respectively. $\%, 34 \%$, the farthest impact ranges of the upper and lower sides are $6.8 \mathrm{~m}$ and $7.8 \mathrm{~m}$ respectively, and the slope of the vertical stress reduction curve gradually decreases, indicating that as the distance between the floor roadway and the coal roadway increases, the unloading of the surrounding rocks on the two sides of the floor roadway The pressure effect gradually weakens and the pressure relief speed gradually slows down.

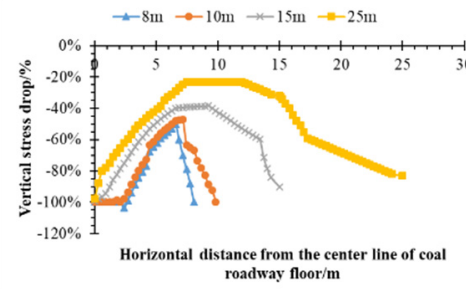

(a) Surrounding rock directly below

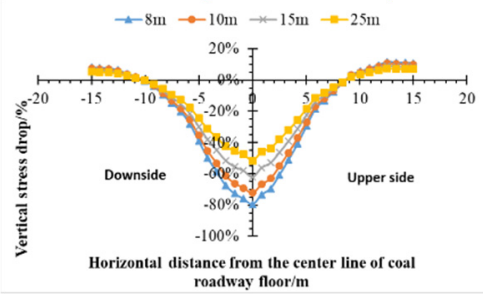

(b) Surrounding rock on both sides below

Fig. 3. The vertical stress reduction curve of the coal roadway floor after the coal roadway is driven in different distances

It can be seen from Figure 3 (a) that after the coal roadway is excavated, when the distance between the floor roadway and the coal roadway is $8 \mathrm{~m}, 10 \mathrm{~m}, 15 \mathrm{~m}$, and $25 \mathrm{~m}$ respectively, the surrounding rock directly below the centerline of the coal roadway floor (between the coal roadway and the floor roadway) The vertical stress reduction curve presents a "convex" curve, that is, the vertical stress reduction in the middle is small, and the vertical stress reduction on both sides is large; the pressure relief effect is more obvious in the range of $6 \mathrm{~m}$ below the centerline of the coal roadway floor and $6 \mathrm{~m}$ above the centerline of the roof of the floor roadway. It is 
$39 \% \sim 100 \%$, and the pressure relief degree of the floor roadway roof is slightly greater than that of the coal roadway roof.

It can be seen from Figure 3 (b) that when the distance between the floor roadway and the coal roadway is $8 \mathrm{~m}$, $10 \mathrm{~m}, 15 \mathrm{~m}$, and $25 \mathrm{~m}$, the maximum vertical stress reduction amplitudes of the surrounding rocks above the centerline of the coal roadway floor are $80 \%, 72 \%, 62 \%$, respectively. $\%, 51 \%$, the farthest influence range of the upper and lower sides is $8.5 \mathrm{~m}$ and $10 \mathrm{~m}$, respectively, and the slope of the vertical stress reduction curve gradually decreases, indicating that as the distance between the floor roadway and the coal roadway increases, the unloading of the surrounding rocks on the two sides of the floor roadway The pressure effect gradually weakens and the pressure relief speed gradually slows down.

\section{Stress distribution characteristics in the horizontal direction}

When the floor roadway is located at different horizontal distances below the coal roadway, after the floor roadway and coal roadway are both excavated, the vertical stress cloud diagram of the coal and rock strata above the floor roadway is shown in Figure 4.

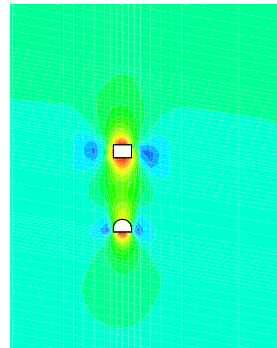

(a) Right below

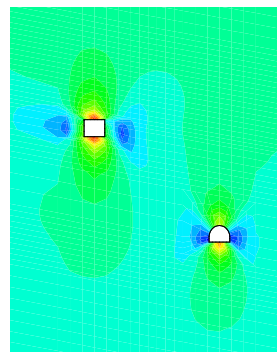

(b) Internal error $10 \mathrm{~m}$

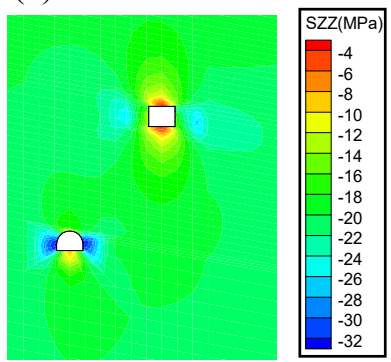

(d) External error $10 \mathrm{~m}$

Figure 4. Vertical stress cloud diagram when the coal roadway and floor roadway are at different horizontal distances

It can be seen from Figure 4 (a) that when the floor roadway is located directly below the coal roadway, the floor roadway has a more obvious decompression effect on the overlying coal and rock mass, and after the coal roadway is excavated, the coal roadway roof and floor are relieved for the second time., The vertical stress relief effect of the roof and floor of the coal road is significant. It can be seen from Figure 4 (b) that when the floor roadway is located within $10 \mathrm{~m}$ below the coal roadway, the floor roadway basically has no decompression effect on the coal roadway, and the right side of the coal roadway is located in the stress concentration area of the floor roadway and coal roadway. It can be seen from
Figure 4(c) that when the floor roadway is located $20 \mathrm{~m}$ below the coal roadway, the floor roadway basically has no decompression effect on the coal roadway, and has little influence on the right side of the coal roadway. It can be seen from Figure 4(d) that the pressure relief effect of the floor roadway is basically the same when the floor roadway is located below the coal roadway when it is $10 \mathrm{~m}$ away from the outside and when it is $10 \mathrm{~m}$ away from the inside. Comprehensive analysis shows that as the horizontal distance between the floor roadway and the coal roadway increases, the pressure relief effect of the floor roadway on the overlying coal and rock mass is gradually reduced. When the horizontal distance between the two is $10 \mathrm{~m}$, the coal roadway and the floor roadway have one side. The roadway is located in the stress concentration area after the roadway is excavated, which is not convenient for roadway maintenance. When the floor roadway is located directly below the coal roadway, the floor roadway has the best decompression effect on the overlying coal and rock mass, and has little effect on the two sides of the roadway.

\section{Conclusion}

When the distance between floor roadway and coal roadway is $8 \mathrm{~m}, 10 \mathrm{~m}, 15 \mathrm{~m}, 25 \mathrm{~m}$, the vertical stress drop of surrounding rock directly below the centerline of coal roadway floor (between coal roadway and floor roadway) presents an "upward convex" curve, that is, the middle is vertical. The stress drop is small, and the vertical stress drop on both sides is large. The slope of the vertical stress reduction curve gradually decreases, indicating that as the distance between the floor roadway and the coal roadway increases, the pressure relief effect of the surrounding rocks of the floor roadway gradually weakens and the pressure relief speed gradually slows down.

As the horizontal distance between the floor roadway and the coal roadway increases, the pressure relief effect of the floor roadway on the overlying coal and rock mass gradually decreases. When the horizontal distance between the two is $10 \mathrm{~m}$, both the coal roadway and the floor roadway have one side of the roadway after the roadway is driven. In the stress concentration area, it is not convenient for roadway maintenance. When the floor roadway is located directly below the coal roadway, the floor roadway has the best decompression effect on the overlying coal and rock mass, and has little effect on the two sides of the roadway.

\section{Acknowledgments}

This work was financially supported by the national key research and development program of China (2017YFC0804206) , General project of Chongqing Research Institute Co., Ltd (2019YBXM31), General project of Chongqing Research Institute Co., Ltd (2020YBXM22). 


\section{References}

1. Li S Q, Long Z G, Luo W D, Xie Q X, Zhao X. (2012) Numerical simulation of mining protection range of protective seam under coal seam group J. Chinese Safety Science Journal, 22(06): 34-40.

2. Xue H J, Song J C, Li Z Z, Li J P, Chen C T, Cheng $Z$. (2013) Numerical analysis of surrounding rock stress field in deep rock tunnel excavation J. China Mining Industry, 22(05): 83-87.

3. Jin $\mathrm{H} \mathrm{W}$, Xiao Q, Li S G, Xu G . (2017) Characterization of stress field structure of surrounding rock of roadway and analysis of failure factors J. Coal Science and Technology , 45(09): 9296.

4. Tang Z, Pan Y S, Zhu X J, Cui N X. (2015) Stress field analysis of surrounding rock of straight-wall arched roadway J. Civil Construction and Environmental Engineering, 37(03): 79-85.

5. Nie J. (2015) The crack evolution law of the overlying coal seam in the long-distance mining under the protective layer[J]. Coal Technology, 34(09): 41-44. 